Sādhanā Vol. 36, Part 2, April 2011, pp. 141-152. (C) Indian Academy of Sciences

\title{
Optimization of processing parameters in induction hardening using response surface methodology
}

\author{
AMIT KOHLI ${ }^{\mathrm{a}, *}$ and HARI SINGH ${ }^{\mathrm{b}}$ \\ ${ }^{a}$ Mechanical Engineering Department, DAV Institute of Engineering and \\ Technology, Kabir Nagar, Jalandhar City, Punjab 144 008, India \\ ${ }^{\mathrm{b}}$ Mechanical Engineering Department, National Institute of Technology, Kurukshetra \\ 136119 , India \\ email: mechanical_amit@yahoo.com; hsingh_nitk@rediffmail.com
}

MS received 6 November 2009; revised 10 December 2010; accepted 25 February 2011

\begin{abstract}
In this paper, an effective procedure of response surface methodology (RSM) has been utilized for finding the optimal values of process parameters while induction hardening of AISI 1040 under two different conditions of the material i.e., rolled and normalized. Various process parameters, such as feed rate (speed at which the induction coil moves, which is measured in $\mathrm{mm} / \mathrm{sec}$ ), current, dwell time (time after which heat intensity starts to heat work piece in seconds) and gap between the work piece and induction coil have been explored by experiments. Hardness at two different conditions has been considered as performance characteristic. The experiment plan was based on rotatable, central composite design (CCD). The experimental results showed that the proposed mathematical models suggested could describe the performance indicators within the limits of the factors being investigated. The obtained optimal process parameters have been predicted and verified by confirmation experiments. Microstructure and SEM (scanning electron microscope) analyses were also done for justification of the work.
\end{abstract}

Keywords. Induction hardening; central composite design; design expert software; response surface methodology.

\section{Introduction}

Since 1980's the processes of surface strengthening (hardening) of steel with the use of high frequency induction (Miller \& Lagoudas 1980) have found ever-increasing applications to improve the performance and life of parts used in aerospace and automobile engineering. Thin surface layers $(0.25$ to $2.3 \mathrm{~mm})$ of the work piece made of steel or cast iron is hardened by induction hardening process. Most important characteristic for the material hardening is the hardness value (Bodart et al 2001). Kayacan (2004) took distance between coil and material, cooling time,

*For correspondence 
applied power and frequency as effecting parameters. Optimized fuzzy solution of the induction hardening has been compared with the experimental results conducted by Kayacan (1991). Here experimental results and fuzzy results confirm each other. Totik et al (2003) took heating time (feed rate) and temperature as process parameters and concluded that depending on the process parameters selected the induction hardening treatment helped in the improvement of wear characteristics. Material selected by him was AISI 4140 steel. Stich et al (2000) took four different variables feed rate, gap between coil and work piece, quench distance and part temperature and applied design of experiment and neural network approach in case of the induction hardening process. By using the methodology developed in his research, a significant improvement in the process was achieved. Ge et al (2006) in their paper analysed relationship of hardening parameters like voltage and current control of power supply, heating time control and part speed control for scan induction hardening. Dynamic models for power supply current and part moving speed have been presented. The authors proposed that future work is modelled towards optimization control of induction hardening process. Lai et al (2009) studied large-sized slewing bearings subjected to surface hardening by means of induction heating. It was reported that the load-carrying capacity of the bearings was mainly dependent on the case-depth (CD). It is of crucial importance for bearing manufacturers to ensure that sufficient CD is produced to meet the bearing capacity for the required applications. The calculation method for the load-carrying capacity of surface-hardened bearings, especially the induction-hardened bearings, is not well-established compared to through-hardened bearings.

From the above descriptive analysis, it is evident that the optimal design is becoming one of the primary challenges of technology industry. In this paper, the optimal values of process parameters have been numerically found out using the quadratic model of RSM. Since time and money are involved while performing the experimental runs, it is pertinent to reduce the number of runs while not compromising the desired goals. For the achievement of the above mentioned objective some strategies like central composite designs in RSM have been frequently used (Cochran $\&$ Cox 1992). Also RSM is one of the most widely used methods to solve the optimization problem in the manufacturing environments (Grum \& Slab 2004; Ozcelik \& Erzurmlu 2005; Kansal et al 2005; Oktem et al 2005). Response surface methodology (RSM) is a collection of mathematical and statistical techniques that are useful for the modelling and analysis of problems in which a response of interest is influenced by several variables and the objective is to optimize this response.

\section{Experimental set-up}

\subsection{Experimental apparatus}

For performing the experiments, the medium frequency induction hardening machine $(10 \mathrm{kHz}$, $120 \mathrm{~kW}$ and spindle speed 400 r.p.m.), make 'unitherm' has been used. The length of the work

piece used is $305 \mathrm{~mm}$ (distance between two spindles) and its diameter is $25 \mathrm{~mm}$. A source of high frequency electricity has been used to drive a large alternating current through a copper coil. The passage of current through this coil generated a very intense and rapidly changing magnetic field in the space within the work coil. The work piece to be heated was placed within this intense alternating magnetic field where eddy currents were generated within the work piece and resistance lead to Joule heating of the metal. The core of the component remained unaffected by this treatment. Induction temperature was between $850^{\circ} \mathrm{C}$ and $900^{\circ} \mathrm{C}$. It was controlled by setting the various process parameters. 
Table 1. Process parameters with their values at three levels.

\begin{tabular}{llccc}
\hline Factors & Process parameters & Level I & Level II & Level III \\
\hline A & Feed rate $(\mathrm{mm} / \mathrm{s})$ & 2 & 3 & 4 \\
B & Dwell time (sec) & 5 & 6 & 7 \\
C & Current (Ampere) & 125 & 130 & 135 \\
D & Gap between work piece and induction coil (mm) & 5 & 6 & 7 \\
\hline
\end{tabular}

\subsection{Work piece material}

The hardness performance tests after induction hardening at two different conditions viz., asrolled and normalized (normalized condition-Raw material as in rolled condition is heated at $900^{\circ} \mathrm{C}$ for one hour and then cooling is done in air at $25^{\circ} \mathrm{C}$ ) were performed on AISI 1040

Table 2. Design layout.

\begin{tabular}{|c|c|c|c|c|c|c|}
\hline $\begin{array}{l}\text { Run } \\
\text { no }\end{array}$ & $\begin{array}{l}\text { Feed rate } \\
\text { A }(\mathrm{mm} / \mathrm{s})\end{array}$ & $\begin{array}{l}\text { Dwell time } \\
\text { B (sec) }\end{array}$ & $\begin{array}{c}\text { Current } \\
\mathrm{C} \text { (Ampere) }\end{array}$ & $\begin{array}{c}\text { Gap } \\
\mathrm{D}(\mathrm{mm})\end{array}$ & $\begin{array}{l}\text { Hardness at } \\
\text { rolled condition } \\
\text { of material } \\
\text { H (R) (HRC) }\end{array}$ & $\begin{array}{c}\text { Hardness at normalized } \\
\text { condition of } \\
\text { material } \mathrm{H}(\mathrm{N})(\mathrm{HRC})\end{array}$ \\
\hline 1 & 2 & 5 & 125 & 5 & 51 & 52 \\
\hline 2 & 4 & 5 & 125 & 5 & 54 & 55 \\
\hline 3 & 2 & 7 & 125 & 5 & 53 & 54 \\
\hline 4 & 4 & 7 & 125 & 5 & 56 & 57 \\
\hline 5 & 2 & 5 & 135 & 5 & 54 & 56 \\
\hline 6 & 4 & 5 & 135 & 5 & 56 & 57 \\
\hline 7 & 2 & 7 & 135 & 5 & 55 & 57 \\
\hline 8 & 4 & 7 & 135 & 5 & 55 & 56 \\
\hline 9 & 2 & 5 & 125 & 7 & 51 & 52 \\
\hline 10 & 4 & 5 & 125 & 7 & 53 & 54 \\
\hline 11 & 2 & 7 & 125 & 7 & 52 & 53 \\
\hline 12 & 4 & 7 & 125 & 7 & 53 & 55 \\
\hline 13 & 2 & 5 & 135 & 7 & 53 & 54 \\
\hline 14 & 4 & 5 & 135 & 7 & 54 & 56 \\
\hline 15 & 2 & 7 & 135 & 7 & 54 & 55 \\
\hline 16 & 4 & 7 & 135 & 7 & 53 & 54 \\
\hline 17 & 1 & 6 & 130 & 6 & 49 & 50 \\
\hline 18 & 5 & 6 & 130 & 6 & 51 & 52 \\
\hline 19 & 3 & 4 & 130 & 6 & 54 & 56 \\
\hline 20 & 3 & 8 & 130 & 6 & 56 & 58 \\
\hline 21 & 3 & 6 & 120 & 6 & 54 & 56 \\
\hline 22 & 3 & 6 & 140 & 6 & 57 & 58 \\
\hline 23 & 3 & 6 & 130 & 4 & 55 & 56 \\
\hline 24 & 3 & 6 & 130 & 8 & 51 & 53 \\
\hline 25 & 3 & 6 & 130 & 6 & 56 & 57 \\
\hline 26 & 3 & 6 & 130 & 6 & 56 & 57 \\
\hline 27 & 3 & 6 & 130 & 6 & 55 & 57 \\
\hline 28 & 3 & 6 & 130 & 6 & 55 & 57 \\
\hline 29 & 3 & 6 & 130 & 6 & 55 & 56 \\
\hline 30 & 3 & 6 & 130 & 6 & 55 & 56 \\
\hline
\end{tabular}


steel bars. Its composition was $0.45 \%$ Carbon, $0.75 \%$ Manganese, $0.2 \%$ Silicon, $0.05 \%$ Sulphur, $0.07 \%$ Phosphorus and $0.12 \%$ Chromium. Static induction hardening has been performed on the work piece. The hardness of bar when measured in rolled condition was found to be $205 \mathrm{BHN}$ (Brinell hardness number) and in normalized condition 197 BHN. This material is suitable for a wide variety of automotive components like axle and spline shafts (Oberg \& Green 1996).

\subsection{Experimental plan}

In this investigation four factors have been studied and their low and high levels are shown in the table 1. Based on preliminary investigation and review of literature, the range of input parameters which were finally selected is given in table 1 . These values of process parameters of induction hardening were utilized for conducting design of experiments in induction hardening machine of AISI 1040 steel, based on design of experimental process. The response variable investigated was hardness at two different conditions of the material as mentioned earlier.

Based on the foregoing inputs, the complete design layout produced by the software Design Expert version 7.1.6 (Stat- Ease Inc., Minneapolis, 185 MN USA) formed is shown in table 2.

\subsection{Experimental technique}

As shown in table 2, performance tests involved 30 trials (runs) each of rolled and normalized condition of the material. The hardness was measured by Rockwell hardness testing machine for $\mathrm{C}$ scale at $150 \mathrm{Kg}$ load, having diamond indenter at 120 degree.

\section{Results and discussions}

The mean of three value of hardness for each trial is mentioned in the table 2. Further analysis of results were done using the software.

\subsection{Analysis of variance (ANOVA)}

ANOVA table has been used to summarize the test for significance of regression model, test for significance for individual model coefficient and test for lack-of-fit. Summary output revealed that quadratic model is statistically significant for response at the two different conditions. Significant model terms were identified at $95 \%$ significance level Goodness of fit was evaluated from $\mathrm{R}^{2}$ (Coefficient of Correlation) and CV (Coefficient of Variation) in order to check the reliability and precision of the model. Degrees of Freedom (df) mean the number of values that can vary independently of one another. By selecting the backward elimination procedure to automatically reduce the terms that are not significant, the resulting ANOVA table for the reduced quardratic model for hardness at rolled condition is shown in table 3.

The Probability $>$ F for the model in (table 3 ) is less than 0.05 which indicates that the model is significant, which is desirable as it indicates that the terms in the model have a significant effect on the response. In this case $\mathrm{A}, \mathrm{B}, \mathrm{C}, \mathrm{D}, \mathrm{AB}, \mathrm{AC}, \mathrm{AD}, \mathrm{BC}, \mathrm{A}^{2}, \mathrm{D}^{2}$ are significant model terms. The main effect of second order of feed rate was the most significant factor associated with hardness, which was in accordance with the work of Stich et al (2000). Model fitting with the help of Design-Expert software suggested that a quadratic model provided the best fit, and the model was found to have insignificant lack of fit. This was desirable as we wanted a model that fit. The ANOVA table for reduced quadratic model indicated that the model was significant 
Table 3. ANOVA for reduced response surface at rolled condition (response:hardness, $H(R)$ ).

\begin{tabular}{|c|c|c|c|c|c|}
\hline Source & Sum of squares & $\begin{array}{l}\text { Degrees of } \\
\text { freedom }(\mathrm{df})\end{array}$ & Mean square & F Value & $\begin{array}{l}\text { p-value } \\
\text { Probability }>\text { F }\end{array}$ \\
\hline Model & 100.84 & 10 & 10.08 & 41.38 & $<0.0001$ \\
\hline A-Feed rate & 9.38 & 1 & 9.38 & 38.47 & $<0.0001$ \\
\hline B-Dwell time & 3.38 & 1 & 3.38 & 13.85 & 0.0014 \\
\hline C-Current & 12.04 & 1 & 12.04 & 49.41 & $<0.0001$ \\
\hline D-Gap & 15.04 & 1 & 15.04 & 61.72 & $<0.0001$ \\
\hline $\mathrm{AB}$ & 1.56 & 1 & 1.56 & 6.42 & 0.0203 \\
\hline $\mathrm{AC}$ & 3.06 & 1 & 3.06 & 12.57 & 0.0022 \\
\hline $\mathrm{AD}$ & 1.56 & 1 & 1.56 & 6.41 & 0.0203 \\
\hline $\mathrm{BC}$ & 1.56 & 1 & 1.56 & 6.41 & 0.0203 \\
\hline $\mathrm{A}^{2}$ & 48.42 & 1 & 48.42 & 198.68 & $<0.0001$ \\
\hline $\mathrm{D}^{2}$ & 8.75 & 1 & 8.75 & 35.91 & $<0.0001$ \\
\hline Residual & 4.63 & 19 & 0.24 & - & - \\
\hline Lack of fit & 3.30 & 14 & 0.24 & 0.88 & 0.6116 \\
\hline Pure error & 1.33 & 5 & - & - & - \\
\hline Cor. total & 105.47 & 29 & 0.27 & - & - \\
\hline Std. Dev. & 0.49 & \multicolumn{3}{|c|}{$\mathrm{R}^{2}$} & 0.95 \\
\hline Mean & 53.87 & & \multicolumn{2}{|l|}{ Adjusted $\mathrm{R}^{2}$} & 0.93 \\
\hline C.V. $\%$ & 0.92 & & \multicolumn{2}{|l|}{ Predicted $\mathrm{R}^{2}$} & 0.88 \\
\hline PRESS & 12.95 & & \multicolumn{2}{|c|}{ Adequate precision } & 26.4 \\
\hline
\end{tabular}

at $\mathrm{p}<0.0001$, and it's Lack of fit, 0.88 was not significant. The $\mathrm{R}^{2}$ value was high, close to one, which was desirable. $95 \%$ of $\mathrm{R}^{2}$ explains that this much percentage of the variability of result. The predicted $\mathrm{R}^{2}$ value was in reasonable agreement with the adjusted $\mathrm{R}^{2}$. Adequate precision measures signal to noise ratio was computed by dividing the difference between the maximum predicted response and the minimum predicted response by the average standard deviation of all predicted responses. Ratios greater than 4 are desirable. In this particular case the value was 26.4 which were well above 4 , which indicated adequate signals to use this model to navigate the design space. PRESS stands for 'Prediction Error Sum of Squares' and it is a measure of how well the model for the experiment is likely to predict the responses in a new experiments. Small values of PRESS are desirable. In this case the value was 12.95. When feed rate, dwell time, current and gap between the induction coil and work piece were $3.04 \mathrm{~mm} / \mathrm{s}, 7 \mathrm{sec}, 135$ ampere, $5.28 \mathrm{~mm}$, then the optimum value of hardness was $56 \mathrm{HRC}$. The ramp function is an elementary unary real function, easily computable as the mean of its independent variable and its absolute value. Ramp function graph for rolled condition of the material for maximum hardness is shown in figure1. It revealed that what shall be the value of parameters to obtain maximum value of hardness for different process parameters.

The desirability value of 0.926 corresponded to the maximum value of hardness in the given range of parameters during rolled condition of the material. The same procedure has been applied on response, hardness at normalized conditions. By selecting the backward elimination procedure to automatically reduce the terms that were not significant, the resulting ANOVA table for the reduced quardratic model for hardness at normalized condition is shown in table 4. The ANOVA table for quadratic model indicated that the model was significant at $p \leq 0.0001$, and it's lack-of-fit, 1.17, was not significant. In this case A, B, C, D, AB, AC, BC, $\mathrm{A}^{2}, \mathrm{D}^{2}$ are significant model terms. The lack-of-fit can also be said to be insignificant. 


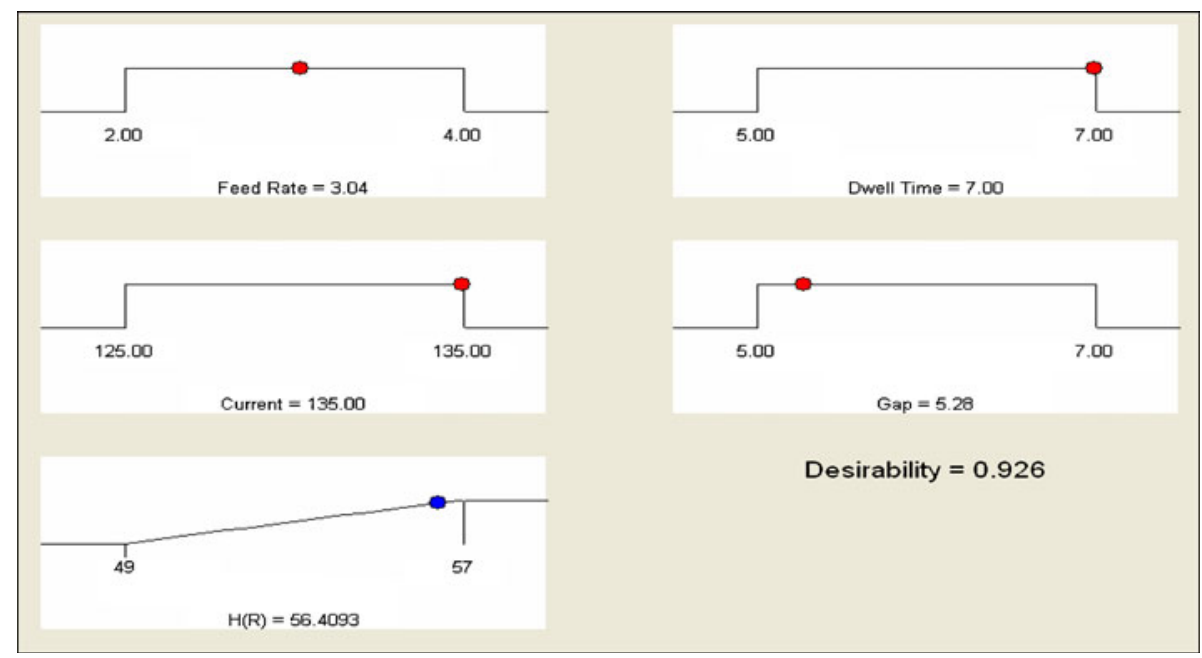

Figure 1. Ramp function graph for rolled condition of the material and response as hardness.

When feed rate, dwell time, current and gap between the induction coil and work piece were $3.13 \mathrm{~mm} / \mathrm{s}, 5 \mathrm{sec}, 135$ ampere, $5.37 \mathrm{~mm}$, then the optimum value of hardness was $57.8 \mathrm{HRC}$. Ramp function graph for normalized condition of the material for maximum hardness is given in figure 2.

Desirability is an objective function that ranges from zero outside of the limits to one at the goal. The numerical optimization finds a point that maximizes the desirability function. The

Table 4. ANOVA for reduced response surface at normalized condition (response:hardness, $H(N)$ ).

\begin{tabular}{|c|c|c|c|c|c|}
\hline Source & Sum of squares & $\begin{array}{l}\text { Degrees of } \\
\text { freedom }(\mathrm{df})\end{array}$ & Mean square & F Value & $\begin{array}{l}\mathrm{p} \text {-value } \\
\text { Probability }>\mathrm{F}\end{array}$ \\
\hline Model & 110.77 & 9 & 12.31 & 40.85 & $<0.0001$ \\
\hline A-Feed rate & 9.38 & 1 & 9.38 & 31.11 & $<0.0001$ \\
\hline B-Dwell time & 3.38 & 1 & 3.38 & 11.20 & 0.0032 \\
\hline C-Current & 12.04 & 1 & 12.04 & 39.97 & $<0.0001$ \\
\hline D-Gap & 12.04 & 1 & 12.04 & 39.97 & $<0.0001$ \\
\hline $\mathrm{AB}$ & 1.56 & 1 & 1.56 & 5.19 & 0.0339 \\
\hline $\mathrm{AC}$ & 5.06 & 1 & 5.06 & 16.80 & 0.0006 \\
\hline $\mathrm{BC}$ & 3.06 & 1 & 3.06 & 10.16 & 0.0046 \\
\hline $\mathrm{A}^{2}$ & 59.42 & 1 & 59.42 & 197.21 & $<0.0001$ \\
\hline $\mathrm{D}^{2}$ & 9.25 & 1 & 9.25 & 30.71 & $<0.0001$ \\
\hline Residual & 6.03 & 20 & 0.30 & - & - \\
\hline Lack of fit & 4.69 & 15 & 0.31 & 1.17 & 0.4656 \\
\hline Pure error & 1.33 & 5 & 0.27 & - & - \\
\hline Cor. total & 116.80 & 29 & - & - & - \\
\hline Std. Dev. & 0.55 & & \multicolumn{2}{|l|}{$\mathrm{R}^{2}$} & 0.95 \\
\hline Mean & 55.20 & & \multicolumn{2}{|l|}{ Adjusted $\mathrm{R}^{2}$} & 0.92 \\
\hline C.V. $\%$ & 0.99 & & \multicolumn{2}{|l|}{ Predicted $R^{2}$} & 0.88 \\
\hline PRESS & 13.83 & & \multicolumn{2}{|c|}{ Adequate precision } & 26.6 \\
\hline
\end{tabular}




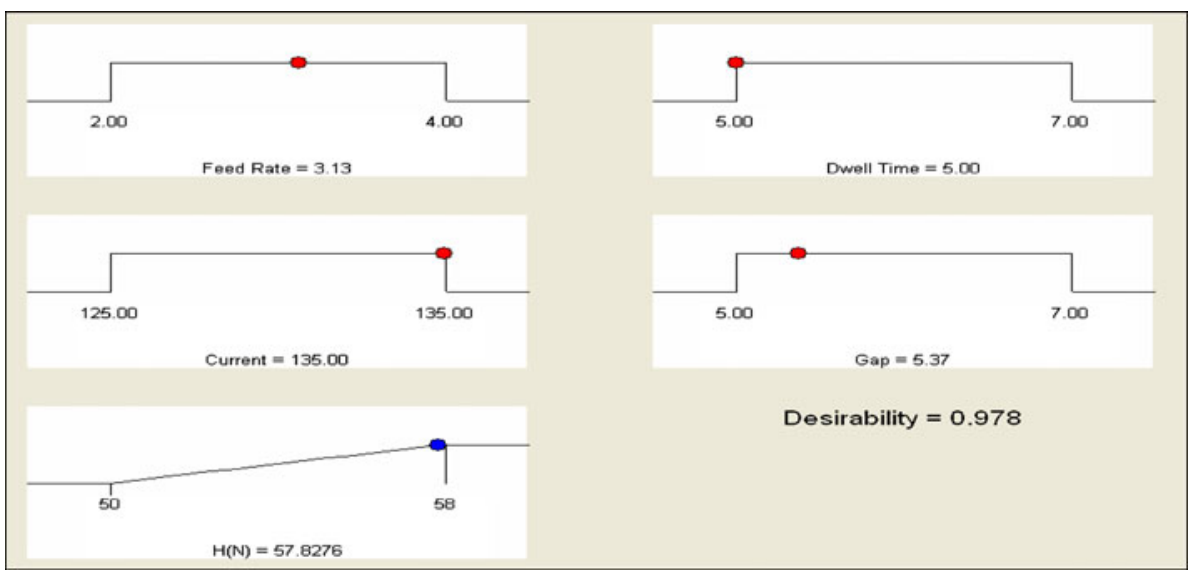

Figure 2. Ramp function graph for normalized condition of the material and response as hardness.

desirability value of 0.978 corresponded to the maximum value of hardness in the given range of parameters during normalized condition of the material.

The 3D surface graphs and contour for the response is shown in figure 3 for rolled condition of the material. The figure shows the effect of dwell time and feed rate on the response as hardness at rolled condition. The curvilinear profile in the figure is in accordance with the quadratic model fitted. From these figures, it is clear that feed rate increases up to a certain limit then decreases; the optimum value of hardness is obtainable when the feed rate is somewhere at the middle of the feed rate range experimented. This is consistent with the fact that the heat intensity of work piece increases when the feed rate value is from 2 to $3 \mathrm{~mm} / \mathrm{sec}$ and then decreases as the feed

(a)

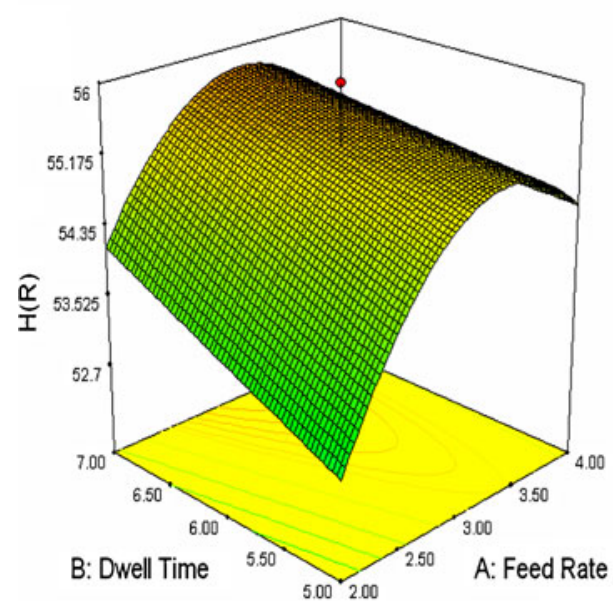

(b)

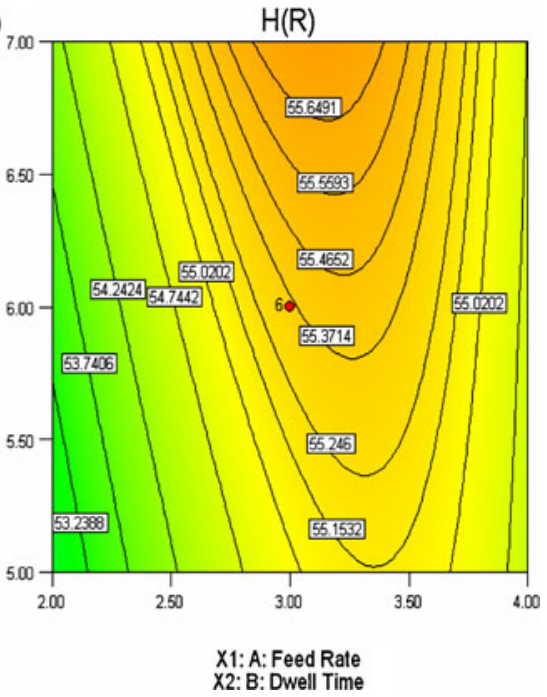

Figure 3. During rolled condition of the material (a) 3D surface graph; (b) contour plot and response as hardness. 
(a)

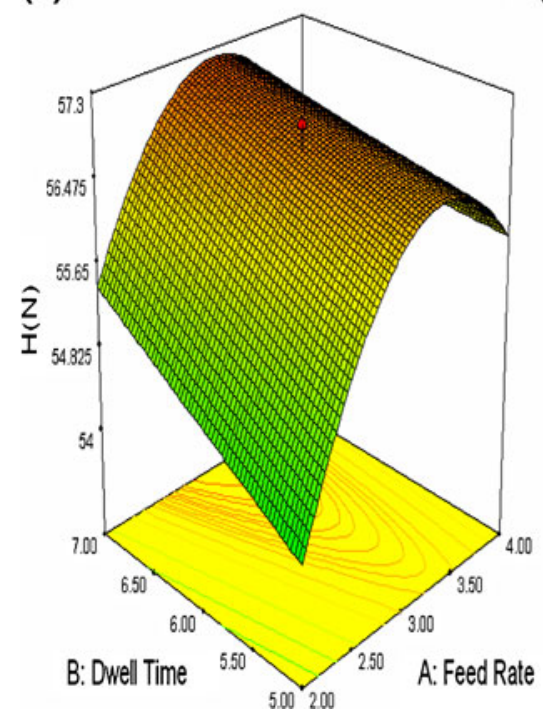

(b)

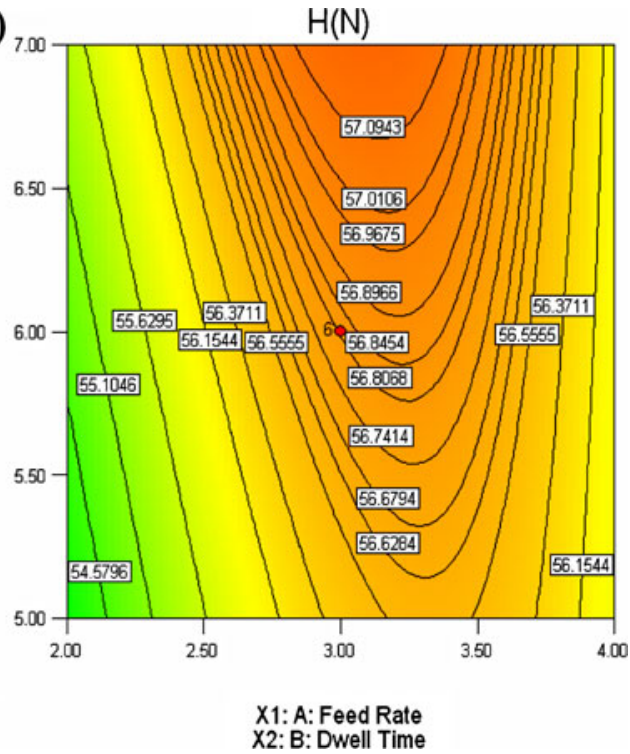

Figure 4. During normalized condition of material (a) 3D surface graph; (b) contour plot and response as hardness.

rate value increases from 3 to $4 \mathrm{~mm} / \mathrm{sec}$ and it is found that the square of feed rate (second order of feed rate) is a significant model term. From the figure it can also be seen that hardness shows a linear increase with increase in dwell time.

Likewise, figure 4 is also similar to figure 3, therefore the comments given previously for rolled condition hold true for the normalized condition of the material.

\subsection{Regression equations of various responses}

The regression coefficients of the second order equations have been obtained by using the experimental data (tables 3 and 4). The regression equations (1 and 2) for the response characteristics as a function of four input parameters at two different conditions of the material (rolled and normalized) considered in this experiment are given below. The insignificant coefficients (identified from ANOVA) have been omitted from the equations.

$$
\begin{aligned}
\mathrm{H}(\mathrm{R})= & {[-88.27+23.57 \times \text { Feed rate }+9.43 \times \text { Dwell time }+0.77 \times \text { Current }+6.8} \\
& \times \text { Gap }-0.31 \times \text { Feed rate } \times \text { Dwell time }-0.09 \times \text { Feed rate } \times \text { Current } \\
& -0.31 \times \text { Feed rate } \times \text { Gap }-0.06 \times \text { Dwell time } \times \text { Current }-1.3 \\
& \left.\times(\text { Feed rate })^{2}-0.55 \times(\text { Gap })^{2}\right] .
\end{aligned}
$$

$$
\begin{aligned}
\mathrm{H}(\mathrm{N})= & {[-112.76+25.79 \times \text { Feed rate }+12.68 \times \text { Dwell time }+1.01 \times \text { Current }} \\
& +6.13 \times \text { Gap }-0.31 \times \text { Feed rate } \times \text { Dwell time }-0.11 \times \text { Feed rate } \\
& \times \text { Current }-0.09 \times \text { Dwell time } \times \text { Current }-1.44 \times(\text { Feed rate })^{2} \\
& \left.-0.57 \times(\text { Gap })^{2}\right] .
\end{aligned}
$$


Table 5. Confirmation table for RSM regression equation.

\begin{tabular}{lcccc}
\hline Responses & Experiment no. & Experiment value & Model value & Percentage variation \\
\hline \multirow{3}{*}{ H (R) } & 30 & 51 & 51.12 & $0.23 \%$ \\
& 6 & 56 & 55.06 & $1.52 \%$ \\
& 9 & 49 & 49.46 & $0.93 \%$ \\
$\mathrm{H}(\mathrm{N})$ & 14 & 55 & 55.96 & $1.71 \%$ \\
& 21 & 52 & 55.84 & $6.87 \%$ \\
& 3 & 56 & 55.21 & $1.43 \%$ \\
\hline
\end{tabular}

\subsection{Confirmation experiments}

In order to validate the regression equations, experimental data were compared with data obtained by putting the same experimental conditions in the regression equations. The results are given in table 5 .

The results tabulated in table 5 shows that experimental data and data obtained by regression equation closely correlate with each other which validate the regression equations developed.

\subsection{Multiple response optimizations}

Model equations were simultaneously solved to find the optimal process variables. DesignExpert software was used for maximizing hardness both in rolled and normalized condition. The optimal value for hardness obtained were 56.4 HRC and 57.8 HRC respectively for rolled and normalized condition at feed rate of $3.21 \mathrm{~mm} / \mathrm{s}$, dwell time $5 \mathrm{sec}$, current 135 Amperes and gap between material and inductor coil $5.29 \mathrm{~mm}$ as optimum value of process parameters. Validation experiments conducted at optimal parameters gave 55.8 HRC and 57.6 HRC values of hardness at rolled and normalized condition, in agreement with the predicted responses. All the values were within $95 \%$ prediction interval. Thus the optimum value of hardness desired was obtained in normalized condition of the material. Ramp function graph for rolled and normalized condition for optimum hardness is given in figure 5 .

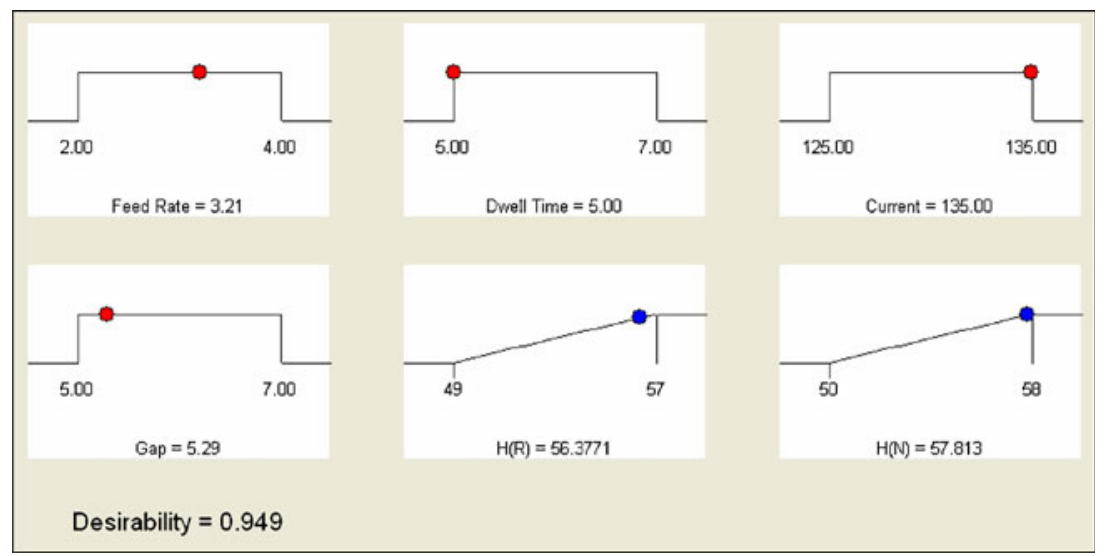

Figure 5. Ramp function graph for rolled and normalized condition for optimum hardness. 

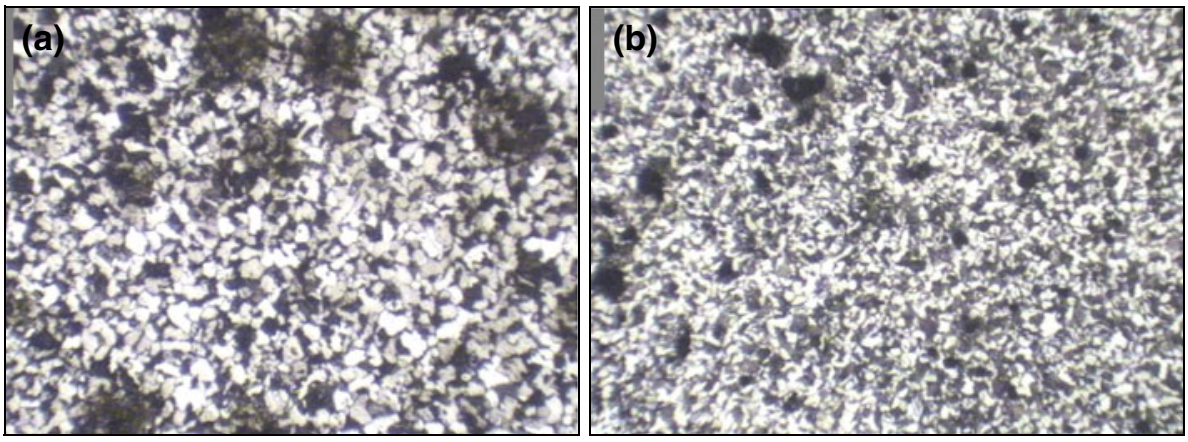

Figure 6. Light microscope photomicrograph of the surface of induction case hardened AISI 1040 steel at $150 \times, 2 \%$ nital before induction hardening; (a) as-rolled, (b) normalized condition of the material.

\section{Microstructure and scanning electron microscope (SEM) analysis}

Uniform distribution of carbon cannot be assumed in the case of induction hardening. The time spent at the austenitizing temperature can be so brief that carbon cannot diffuse to a uniform concentration throughout the microstructure. Induction heat treatment specifications sometimes include a requirement that the microstructure must be $100 \%$ tempered martensite to ensure that the hardness does reflect the material's mechanical properties. But the determination of $100 \%$ martensite can be subjective and difficult to determine optically (Tartaglia \& Eldis 1984). Light microscope photomicrograph of the surface of induction case hardened AISI 1040 steel at $150 \times$, $2 \%$ nital is shown in the figures $6 \mathrm{a}$ and $\mathrm{b}$ at rolled and normalized condition. The percentage of pearlite was found to be $70.45 \%$ and that of ferrite $29.54 \%$ at rolled condition of the material and $75.14 \%$ (pearlite) and $24.85 \%$ (ferrite) at normalized condition of the material.

As in light microscope photomicrograph the martensite structure was not seen. This introduced some ambiguity. So SEM photomicrographs of the steel parts were then taken for the material having low hardness and the optimal process parameter material. The microstructure at low hardness contained martensite having ferrite greater than $10 \%$ and at optimal almost $100 \%$ martensite was observed which indicated the distribution of uniform hardness as shown in figures $7 \mathrm{a}$ and $\mathrm{b}$.
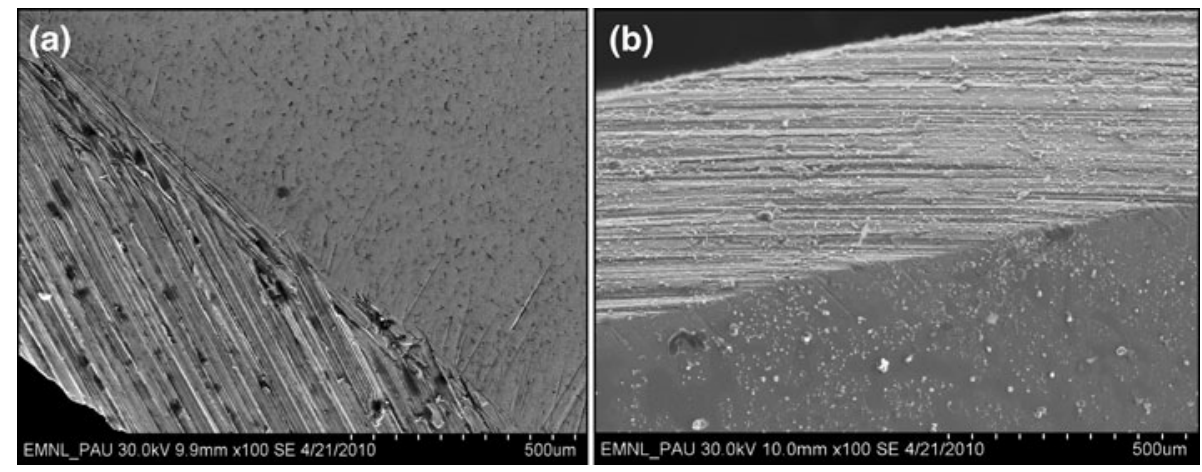

Figure 7. SEM photomicrographs after induction hardening (a) at low hardness, (b) optimal condition of the material. 


\section{Conclusions}

The experimental investigations have shown that the effect of process parameters such as feed rate, dwell time, current and gap between material and inductor coil on the hardness of AISI 1040 steel under two different conditions i.e., rolled and normalized during induction hardening. The optimal values for hardness obtained were 56.4 HRC and 57.8 HRC respectively for rolled and normalized condition at feed rate of $3.21 \mathrm{~mm} / \mathrm{s}$, dwell time $5 \mathrm{sec}$, current 135 Amperes and gap between material and inductor coil $5.29 \mathrm{~mm}$ as optimum value of process parameters. The results tabulated in table 5 show that experimental data and data obtained by regression equation closely correlate each other which validate the regression equations developed. Hence it can be concluded that for making shafts, axles or automobile components from medium carbon steel, raw material should be first normalized and then induction hardened so that uniform hardness of the material can be obtained.

Our deep sense of gratitude to Shri Ashok, Director, Central Institute of Hand Tool and Shri. WC Khosla, Chief Metallurgist, Krishna Engineering Works, Jalandhar for providing induction hardening and metallurgy lab facilities. We are also grateful to Prof C L Kochher, Regional Director DAV Technical Institutes and Dr. A S Arora, Principal DAV Institute of Engineering and Technology of for their valuable support and encouragement to publish this paper.

\section{References}

Bodart O, Bourean A V, Touzani R 2001 Numerical investigation of optimal control of induction heating process, Applied Mathematical Model, 25: 697-712

Cochran W G, Cox G M 1992 Experimental designs, 2nd ed., New York: Wiley, 335-339

Ge Y, Hu R, Zhang Z 2006 Optimization control of induction hardening process; qingtong shen mechatronics and automation, Proceedings of IEEE International Conference on Mechatronics and Automation, Luoyang; China, 1126-1130

Grum J, Slab J M 2004 The use of factorial design and response surface methodology for fast determination of optimal heat treatment conditions for different Ni-Co-Mo surface layers, J. Materials Processing Technol. 155-156: 2026-2032

Kansal H K, Singh S, Kumar P 2005 Parametric optimization of powder mixed electrical discharge machining by response surface methodology, J. Materials Processing Technol., 169(3): 427436

Kayacan M C 1991 Design and construction of a Set-up for induction hardening, M Sc thesis, University of Gaziantep

Kayacan M C 2004 A fuzzy approach for induction hardening parameter selection, J. Materials and Design, 25(2): 155-161

Lai J, Ovize P, Kuijpers H, Bacchettto A, Ioannides S 2009 Case-depth and static capacity of surface induction-hardened rings, J. ASTM International 6(10): 1-16

Miller D A and Lagoudas D C 1980 Trends in the development of heat-treatment technology, J. Metal Science and Heat Treatment 22(11): 846-850

Oberg E, Green R E 1996 Machinery's handbook, 25 ${ }^{\text {th }}$ ed., New York: Industrial Press

Oktem H, Erzumlu T, Kurtaran H 2005 Application of response surface methodology in the optimization of cutting conditions of surface roughness, J. Materials Processing Technol., 170(1-2): 11-16

Ozcelik B, Erzurmlu T 2005 Determination of effecting dimensional parameters on warpage of thin shell plastic parts using integrated response surface method and genetic algorithm, Int. Communication of Heat and Mass Transfer, 32(8): 1085-1094 
Stich T J, Spoerre J K, Velasco T 2000 The application of artificial neural networks to monitoring and control of an induction hardening process, J. Industrial Technol., 16(1): 1-11

Tartaglia J M, Eldis G T 1984 Core hardenability calculations for carburizing steels. Metallurgical Transactions A, 15A(6): 1173-1183

Totik Y, Sadeler R, Altun H, Gavgali M 2003 The effects of induction hardening on wear properties of AISI 4140 steel in dry sliding conditions, Materials and Design, 24(1): 25-30 